\title{
Design of Learning Objects for Collaboration Promotion and their Effects on Students' Behaviour
}

\author{
Edviges F. C. LIMA, Clauirton A. SIEBRA \\ Informatics Center, Federal University of Paraiba, Joao Pessoa, Brazil \\ e-mail:edvigeslima@gmail.com, clauirton@ci.ufpb.br
}

Received: February 2020

\begin{abstract}
While virtual learning environments (VLEs) present several advantages, such as spacetime flexibility, they are still not including proper opportunities and resources for students to engage in collaborative activities with their peers. Recent approaches, for example, are based on resources that are not standard for VLEs or usual for students. Thus, their integration with VLEs is not simple. This paper conducted a theoretical investigation to identify strategies that could induce collaborative behaviours in students. These strategies were implemented as learning objects running in a VLE and a quasi-experimental research design was conducted with 133 students. The results show that the approach promotes collaborative interactions between students and also tend to improve their learning outcomes. Moreover, learning objects use a conceptualization that is already established over the e-learning community, simplifying their integration with VLEs.
\end{abstract}

Keywords: collaboration, learning objects, virtual learning environments.

\section{Introduction}

The Distance Learning (DL) technology has allowed several higher education courses to be delivered to locations and populations that have historically not been afforded opportunities for involvement in such an educational level (Money and Dean, 2019; Randolph, 2007). In practice, however, this style of education often falls short of what it attempts to accomplish (Choi and Park, 2018; Kumar et al., 2017). The literature stresses that one of the reasons for the DL problems is the difficulty of students to follow the routine of individual studies. Amory (2013), for example, indicates that learning experience should support complex human, social and cultural interactions; include rich contexts and collaborative learning. However, DL environments do not provide or motivate such situations. The study of Blom et al. (2013) also says that "the peers find support from one another for solving the tasks and furthermore, several students regard the social format as being natural because they are already used to the idea of engaging 
in study group practices...In addition to the effect of verbal interactions, these study groups provide the advantage of social facilitation: it is easier to sustain heavy effort associated with the course material in groups than individually - humans are social animals...".

Several recent studies have recognized the importance of social and collaborative behaviour in the learning process. Therefore, the main aims of these studies are focused on the identification of efficient strategies that could induce collaborative behaviour among students. Tseng et al. (2019), for example, argue that the lack of trust usually damages the students' online collaborative learning experience. Thus, they identified the correlations between trust and other elements of the learning environment so the elements with positive correlation could be enforced during virtual interactions. Weidlich and Bastiaens (2019) proposed to enrich the learning environment (Moodle) with plugins (e.g. "Meet the Students", "Course Contacts", and "Dialogue") to foster social-emotional variables that could improve the sociability of such environments, motivating the collaboration among their members. A similar strategy for motivation was proposed by Lin et al. (2018) but, in this case, the authors used a wiki-based approach. Their findings showed that the co-editing wiki platform was effective in assisting collaborative learning in the domain of teaching programming since students who interacted more with their partners on the wiki showed greater program implementation achievements. Stürmer et al. (2018) developed a Moodle-based adaptation that uses the "fast-friendship procedure" to foster collaboration among Moodle users. This procedure is based on Psychologic studies and it assists strangers to establish "interpersonal closeness", which is an important motivator for collaboration. Wengrowicz et al., (2018) investigates the use of Case-based learning, which is an interactive group learning approach that embodies the principles of Socratic inquiry. While this method is already a common pedagogy employed in traditional disciplines, the authors analyse its use in virtual courses.

All these studies share the notion that online learning is as much a social activity as an individual one. However, the quality and quantity of interactivity can vary dramatically from course to course. In general, courses that provide limited forms of interaction tend to present feeble outcomes (Kearsley, 2000) and this is the main reason to create strategies that enforce collaboration. We also corroborate these affirmations but, differently from these approaches, our study aims to induce collaboration by means of object learning designed as resources that are already usual for online students. Furthermore, learning objects use a conceptualization that is already established over the e-learning community, simplifying their integration to VLEs.

Another important difference of this present study is its focus on a particular scenario for collaborative learning that is based on small groups. In order, the literature presents studies that recognize collaboration in small groups as both advantageous and appreciated by students. For example, the study of Gayatan and McEwen (2007) shows that small groups enable students to identify and correct misconceptions more easily and quickly, and improve understanding of the topics being studied. Finegold and Cooke (2006) also support this affirmation and show that small groups are considered as more suitable for group discussions and equal contributions of group members. The study in 
(Springer et al., 1999) found that small groups provide students with a better learning experience and ultimately greater academic achievement. Moreover, the study discussed in (Brindley et al., 2009) reported that students often prefer working in small over large study groups. Besides these evidences, the use of small groups in distance learning platforms is also more feasible because DL learners generally seek flexibility during their activities and they can see participation in group learning as an impediment to their progress. Consequently, the use of small groups (up to 5 members) is also a strategy to attenuate this perception, since it is easier to arrange a common timetable when the process considers few participants.

Based on this introduction, the focus of this present study was on the design of collaborative learning objects, which could be integrated into VLEs using patterns that are already common to the DL community. Therefore, the design of these objects must answer the following questions:

1. Which concepts could be used to induce collaboration in educational settings?

2. Which educational theories support these concepts?

3. How should be the specification of learning objects based on these concepts?

4. How could these objects be used in a Virtual Learning Environment?

After the identification of the collaboration concepts (argumentation, explanation and mutual regulation) and design of the collaborative learning objects, a quasi-experimental study was conducted to verify the following hypothesis: "The use of collaborative learning objects, based on the argumentation, explanation and mutual regulation concepts, can induce collaborative behaviours in small groups of students and, thus, improve their learning process". Two terms are essential in this hypothesis. First, "induce" means that the objects will persuade students to collaborate, rather than enforcing this collaboration. Thus, students will naturally collaborate as part of the activities progress. Second, "improve" means that the learning process will assist students to assimilate knowledge more easily.

The lack of ways to promote students' collaboration in VLEs is certainly a global problem and the Moodle, by far the most worldwide popular VLE, is a practical example of this affirmation. Apart from the importance of collaboration, the current Moodle platform does not properly support interaction/collaboration among students, so students mostly only use the educational content individually. Even providing tools for collaboration, such as the chat rooms and forums, these tools are often used in a very limited or incorrect way. Thus, the development of approaches that can integrate the collaborative behaviour into common resources of Moodle, or other similar VLEs, is still necessary to advance the distance education process.

\section{Collaborative Learning Objects}

Chen et al. (2008) show that student engagement in collaborative activities has been positively related to the quality of learning experiences. Therefore, learning platforms must include opportunities and resources for students to engage in interactive and collaborative activities with their peers. The study of Brindley et al. (2009) lists pedagogi- 
cal benefits, and consequently better learning outcomes, of collaborative learning when it is properly supported for such platforms. These benefits include the development of critical thinking skills, co-creation of knowledge and meaning, reflection and transformative learning (Palloff and Pratt, 2005). This section presents some of the main classical and more recent theories that could provide the basis for collaboration strategies applied to this educational context.

\subsection{Previous Efforts in Collaborative Learning Objects}

As a way to support the development of collaborative learning objects, the study of Fuentes et al. (2008) proposes a design methodology that is based on Collaborative Learning Patterns (CLPs). These patterns are divided into four levels: pedagogic, analysis, design/development, and implementation. This latter level defines the collaborative learning scenarios, which are based on the IMS-LD model, and designers just need to select and instantiate the proper patterns to create their objects. However, the patterns have a high level of abstraction since the IMS-LD specification does not impose a particular pedagogical model or is based on learning theories. The study of Koohang (2004) also discusses the importance of learning objects for collaborative learning, proposing a systematic approach to create such objects. This proposal indicates a set of tools and guidelines that should be considered over the development of objects, such as the use of industrial-standards. Similar to the previous approach, this proposal only gives general directions to design collaborative learning objects.

Cruz-Flores and López-Morteo (2008) propose a model for collaborative learning objects that is particularly based on mobile devices. According to the authors, collaborative activities should take advantage of the mobility and other features of these devices. For example, a learning object about geometrical shapes could explore outdoor activities for students' teams, such as finding buildings, or part of buildings, which have similar shapes that geometrical images. The study of Ayala and Castillo (2008) is also focused on mobile devices and they highlight the power of such devices in supporting social interactivity and, consequently, collaboration. According to the authors, collaborative objects for mobile devices can present learning activities of collaborative nature with the corresponding collaboration scripts, which specify tasks, roles and groups; and information that allows the collaboration with other learners. Note that the mechanism to support collaboration is provided by means of scripts rather than the own structure of the learning object.

Caballe et al. (2012) propose a new paradigm named Collaborative Complex Learning Objects (CC-LO), which are pedagogically designed with reference to the concepts of social and collaborative learning. The key differentiators from the standard LOs include the augmentation of objects with author-generated information (e.g. questions/ answers, alternative flows rather than linear paths, assessments as a strategy to guide the flow evolution, and dependence between objects), their animation that evolve over time, and their high interactivity. Therefore, their proposal is focused on specific resources that are needed to create collaborative objects, rather than explicitly defining 
how the object could promote such a type of collaborative behaviour. Burbaite et al. (2013) discuss a more pragmatic approach, where educational robots represent collaborative learning objects. Their framework promote features such as engagement and exploration by means of collaborative tasks that support and ensure group learning activities and groups work on the critical analysis of provided concepts and information. While the use of educational robotics promotes a further level of motivation for learners, its use is limited and does not offer the required flexibility to the development of an ample set of collaborative learning objects.

The common feature of these approaches is their disassociation with collaborative learning theories. This means, such approaches give the directions for promoting collaboration, while designers must use their expertise to compose the objects based on these directions. Differently, our approach is based on collaborative learning theories and explicitly uses their concepts as fundaments to compose the objects. Independently of the approach, the studies that present experimental results show that learners have higher engagement when using collaborative objects. This fact is demonstrated, for example, in the work of Burbaite et al. (2013), where collaborative learning objects increased the students' engagement in learning as compared to other traditional approaches.

\subsection{Educational Theories and Collaboration}

The first step of this research was to analyse the principles of educational theories, which stress the importance of collaboration in the learning process, and identify which type of interactions are important to induce such a collaboration. Some of the main studies and authors were:

- Piaget (1976) suggests that each individual usually builds his/her knowledge through interactions, explanations, and discussions with other members. During these interactions, individuals must assume the responsibility for his/her learning.

- Aronson et al. (1978) argues that students should be motivated to work into interdependent small groups, rather than all around a teacher. Each student receives a part of the topic to be studied and, when they conclude such a study, they explain their part of the content and try to organize the whole topic such as a puzzle.

- Vygotsky (1979) states that the use of resources for work in groups can lead the discussion of different ideas and, thus, create new cognitive conflicts.

- Siemens (2004) - Connectivism - relates that "Learning (defined as actionable knowledge) can reside outside of ourselves (within an organization or a database) and is focused on connecting specialized information sets, and the connections that enable us to learn more are more important than our current state of knowing". His theory is based on the principle that learning and knowledge rests in diversity of opinions, where "Personal knowledge is comprised of a network, which feeds into organizations and institutions, which in turn feedback into the network, and then continue to provide learning to individual. This cycle of 
knowledge development (personal to network to organization) allows learners to remain current in their field through the connections they have formed.".

- Juwah (2006) discusses the increase of collaborative behaviour by means of mutual regulation, which enables better and global monitoring regarding the comprehension of topics in discussion.

- Mirza and Perret-Clermont (2009) discuss argumentation as a form of interaction that has attracted more attention since it is an appropriate linguistic, logical, dialogical and psychological process that can maintain or trigger reasoning and learning.

Based on the analysis of these theories, we have identified at least three knowledgeproductive interactions that induce collaboration:

(1) Elaborated explanations.

(2) Negotiation of meanings or argumentation.

(3) Mutual regulation of cognitive processes.

The study of Dillenbourg et al. (1996), for example, also investigated these interactions. According to the authors, they are important because "collaborative learning is not always effective; its effects depend on the richness and intensity of interactions engaged in by group members during collaboration". Therefore, these and other similar interactions can increase the level of engagement and, consequently, improve the process of collaboration and learning.

\subsection{Interactions Via Learning Objects}

Given the three interactions (explanation, argumentation and mutual regulation), the next step was to conceptualise these interactions in terms of learning objects, so they could be used in VLEs. A learning object is a collection of content items, practice items, and assessment items that are combined based on a single learning objective (Beck, 2009). Video lessons, for example, are very common forms of learning objects (Benitti, 2018) and they were used in the present study as resources to demonstrate how collaboration could be supported in a virtual learning environment that attends several geographically separated students. In fact, video lessons are considered as one of the most powerful and popular VLE tools since they allow students, for example, to catch up on lectures they missed and learn from a "how-to" screencast. Moreover, several other educational sites, such as Coursera and Udemy, are mostly based on video lessons.

\subsubsection{Argumentation}

Argumentation can be applied to virtually all assignments involving critical reasoning no matter the subject or discipline. The term argument refers to a reasoned attempt to convince the audience to accept a particular point of view about a debatable topic. Therefore, arguments are not irrational. Rather, argumentation represents a reasoned attempt, that is, an effort based on careful thinking and planning where the appeal is to convince the audience to accept a particular point of view (Mirza \& Perret-Clermont, 2009). 
Learning objects that produce conflicting positions tend to intensify argumentation hence the exchange of arguments is necessary to reach agreements. A video lesson of the type interactive-video quiz (in-video quiz) could be used to produce such conflicts. In this case, a small group of students should watch the same video lesson. When an activity (e.g. multiple-choice question) appears during the video streaming, the video pauses and students individually choose an option that answers the question. If a divergence appears among the answers, then the students must argue to reach a consensus so the video can resume its execution.

\subsubsection{Explanation}

Explanation is the most common form of interaction between a lecturer and his/her students. The challenge is to find forms to induce this interaction also among students. During explanations, facts are explained by showing that they can be deduced logically from assumed theoretical premises and already given empirical conditions. Descriptions of the phenomenon enter into such an explanation at two points: as the given empirical conditions and as statements of the facts to be explained. Consequently, commitment to the deductive form of explanation entails commitment to a mode of description that satisfies the logical requirements of deductive claims (Wilson, 1970).

Learning objects that fragment knowledge tend to augment the need for explanations among participants. Consider that the presentation of a topic $\alpha$ is divided into four parts $\alpha_{1} \ldots \alpha_{4}$, so the performance of a final activity $x$ depends on the understanding of $\alpha_{1} \ldots \alpha_{4}$. If we have a small group composed of four students, then each part $\alpha_{i}$ could be sent to a student $s_{i}$. Thus, differently from the previous scenario, students will watch different videos and they need to explain their parts to each other, sharing the knowledge necessary to conclude the activity $x$.

\subsubsection{Mutual Regulation}

Mutual regulation looks at how individuals reciprocally regulate each other's cognitive processes and engage in shared modes of cognitive regulation. Learning objects could enforce mutual regulation, for example, when they create differences in roles by allocating different responsibilities in solving problems. For example, the WiSim experiment (Juwah, 2006) intends to increase collaborative effort via mutual regulation by distributing simulation inputs across different mobile phones and hence requiring students to negotiate values and coordinate their experimental design. Thus, mutual regulation is built in to the use of the roles in conjunction with each other. As questions are asked and answered, or content is clarified and summarised, learning is monitored for accuracy. Moreover, as predications are made they are evaluated for consistency with new content events. In this way, the whole group monitors their on-going comprehension in a process where students mutually regulate their learning.

Learning objects that enable the joint creation of solutions by learners, mutually building on each other's contributions in a coordinated interdependent effort, could foster mutual regulation. An example of this process could be configured, for example, using a whiteboard. After the transmission of a video lesson $\alpha$, an in-video quiz is ac- 
tive and students are lead to construct the solution of this activity in the whiteboard Each student of the group has a pre-defined time $t$ (turn) to contribute to the solution, while other students observer such a construction. After $t$, the construction is paused and the turn passes to the next student. All students must keep the attention on the group resolution since each of them will resume the construction from the point where it was paused. This approach also instigates students to think ahead, following the ongoing line of resolution, so they can better perform in their turn.

Along with his/her turn, a student can diverge and "regulate" the resolution flow, changing the current reasoning, or just continue the resolution by adding more steps. The adjustment of $t$ is an important aspect of this approach. The shorter is $t$, the more interactive is the process. However, $t$ must have a minimum limit value; otherwise, students will not be able to develop so much their reasoning for subparts of the problem during their turns.

\subsection{Practical Specification of Collaborative Learning Objects}

The specification of collaborative learning objects follows the approach of Hernandez et al. (2008), which relies on knowledge about the learning object structure its resources. A Learning Object is a LOM Object - IEEE 1484.12.1.2002 Standard for Learning Object Metadata (IEEE, 2002) - and consists of one or more Assets, which are atomic learning units (e.g. videos, questions, texts, etc.). As proposed in LOM, the object is annotated with different Elements (metadata fields), such as Technical (the technical requirements and technical characteristics of the object), Educational (the educational and pedagogic characteristics of the learning object), and others. The specification indicates the metadata fields that have pre-defined values, and the fields that designers must fill.

Fig. 1 illustrates two different structural views of the Argumentation object, which is represented by only one learning object with one asset of the type "Video", and nq assets of the type "Question".
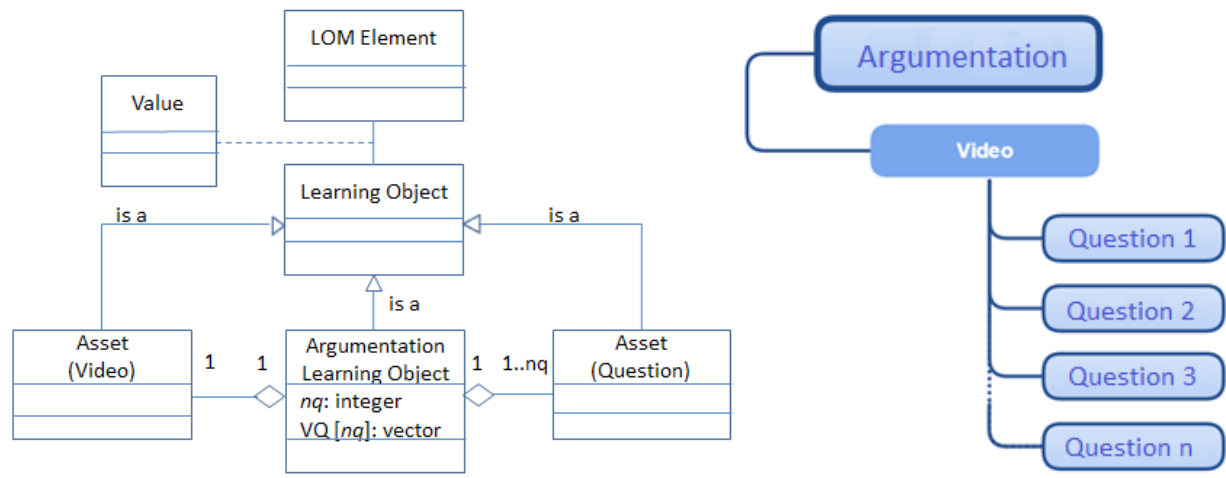

Fig. 1. Composition of the Argumentation object. 
The structure in the left-hand side also shows that the Explanation Learning object extends the traditional learning objects and, thus, inherits all their LOM elements, such as Language and Difficulty. Moreover, the explanation learning objects have two attributes:

- Number of questions $(n q)$ : indicates how many questions are used over the video.

- Temporal vector of questions $\mathrm{VQ}[n q]$ : vector with size $n q$ that contains a sequence of temporal values, which indicate where each question is in the timeline of the video.

Table 1 describes the LOM elements of the argumentation objects that require some attention, such as the use of pre-defined values. The remainder LOM elements must be filled by designers in the same way as any other learning object since they are content-dependent. The LOM standard (IEEE, 2002) does not provide any specific metadata field to indicate the collaborative nature of the object. However, the LOM standard has a metadata field, named Description (Table 1), which indicates how the learning object is to be used. Thus, this field is employed to highlight the collaborative feature of the object.

Fig. 2 presents the structure of the Explanation object. Differently from the Argumentation object, its creation requires $n k$ assets of the type "Video", where the value $n k$ is the suggested number of participants that will use this resource; and $n q$ assets of the type "Question" that are presented at the end of the videos.

As the previous object, the structure in the left-hand side shows that the Explanation Learning object also extends the traditional learning objects and, thus, inherits all their LOM elements. Moreover, explanation learning objects have the following attributes:

- Number of questions $(n q)$ : indicates how many questions are used at the end of the videos.

- Number of videos $(n v)$ : indicates the amount of videos that are used to represent parts of the content.

Table 1

LOM specification for specific fields of the argumentation collaborative learning object.

\begin{tabular}{lll}
\hline Metadata Category & Field & Value \\
\hline Educational & $\begin{array}{l}\text { Interactivity type } \\
\text { Learning Resource Type } \\
\text { Interactivity Level } \\
\text { Typical Learning Time }\end{array}$ & $\begin{array}{l}\text { Pre-defined value: Mixed (active and expositive) } \\
\text { Pre-defined value: High (during the videos) } \\
\text { Content-dependent value. Must be the sum of the learning time } \\
\text { of the assets that compose it (video + average time to answer } \\
\text { the questions) }\end{array}$ \\
& $\begin{array}{l}\text { See section 2.3.1 (how the learning object is to be used) } \\
\text { Content-dependent value. If this value is defined as "x" (e.g. } \\
\text { Difficulty }\end{array}$ \\
& $\begin{array}{l}\text { easy), then none of the assets can have a difficulty value higher } \\
\text { than " } x "\end{array}$ \\
\hline
\end{tabular}




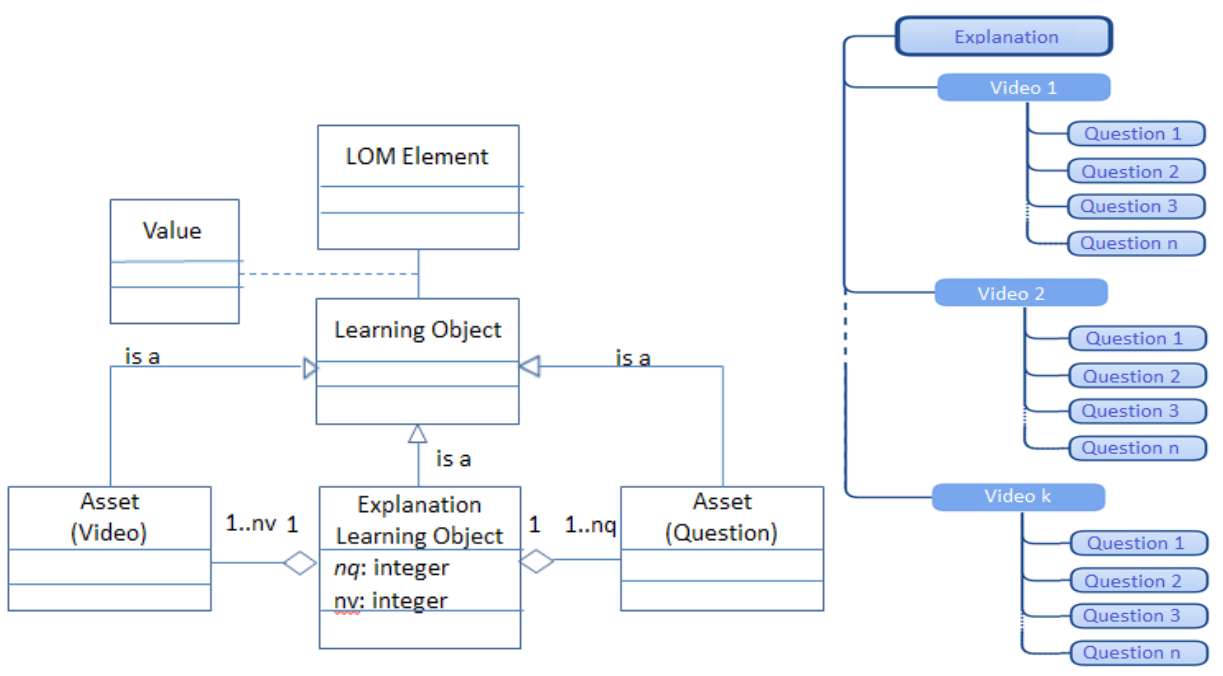

Fig. 2. Composition of the Explanation object.

Table 2 describes the observations regarding the LOM elements of the explanation object that require some attention.

An important observation is associated with the "Typical Learning Time" metadata field. Considering that all participants will start the videos at the same time, they should ideally conclude this video in similar periods to initiate the interactions. However, according to our experiments, this situation rarely happens because students require different times to understand the content of their videos. For example, students with problems of concentration may tend to frequently stop/repeat parts of the video.

Finally, Fig. 3 illustrates the structure of the Mutual Regulation object. It is composed of two objects: "Video" and "Problem Statement". This latter object is a type of evaluation more general than "Question". This means, every Question may be a Problem Statement but a Problem Statement is not necessarily a Question.

Table 2

LOM specification for specific fields of the explanation collaborative learning object

\begin{tabular}{lll}
\hline Metadata Category & Field & \multicolumn{1}{c}{ Value } \\
\hline Educational & $\begin{array}{l}\text { Interactivity type } \\
\text { Learning Resource Type } \\
\text { Interactivity Level }\end{array}$ & $\begin{array}{l}\text { Pre-defined value: Mixed (active and expositive) } \\
\text { Pre-defined value: Video and Questionnaire } \\
\text { Pre-defined value: High (at the end of the videos) } \\
\text { Typical Learning Time } \\
\text { Content-dependent value. The duration of the videos must be } \\
\text { similar, considering a maximum difference of } 10 \text { seconds }\end{array}$ \\
& $\begin{array}{l}\text { See section 2.3.2 (how the learning object is to be used) } \\
\text { Content-dependent value. If this value is defined as "x" (e.g. } \\
\end{array}$ & $\begin{array}{l}\text { easy), then none of the assets can have a difficulty value } \\
\text { higher than " } x "\end{array}$ \\
&
\end{tabular}




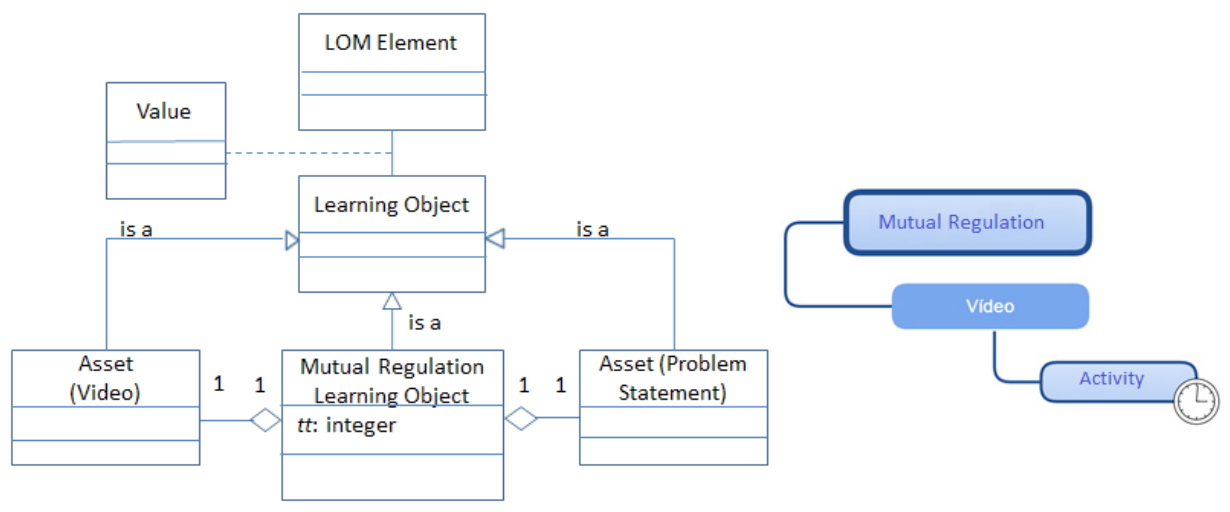

Fig. 3. Composition of the Mutual Regulation object.

Table 3 describes the observations regarding specific LOM elements of the mutual regulation objects that require some attention.

According to the observation in the "Typical Learning Time" metadata field, each participant of the interaction has a time $t t$ to develop a solution. After this time, the control of the resolution passes to another participant. This cycle continues until the activity is concluded. This process states an informal correspondence between $t t$ and the difficulty of the activity. If the activity is classified as easy, $t t$ can be lower than when the activity is classified as hard.

Note that the content of the collaborative learning objects are defined by designers, so the use of these objects does not present restrictions regarding the kind/age of students. Rather, collaborative learning objects can be specified for diverse contexts. As any other learning object, the value of these parameters must be informed in the Context (school, higher education, training, other) and Typical Age Range metadata fields.

Table 3

LOM specification for specific fields of the mutual regulation collaborative learning object

\begin{tabular}{lll}
\hline Metadata Category & Field & Value \\
\hline Educational & $\begin{array}{l}\text { Interactivity type } \\
\text { Learning Resource Type } \\
\text { Interactivity Level }\end{array}$ & $\begin{array}{l}\text { Pre-defined value: Mixed (active and expositive) } \\
\text { Pre-defined value: Very High }\end{array}$ \\
& $\begin{array}{l}\text { Typical Learning Time } \\
\text { Content-dependent value. This value must consider the "Turn } \\
\text { Time" }(t t) \text {, which indicates the time that each participant has to } \\
\text { conclude or resume the resolution of an activity }\end{array}$ \\
& $\begin{array}{l}\text { See section } 2.3 .3 \text { (how the learning object is to be used) } \\
\text { Difficulty }\end{array}$ \\
& $\begin{array}{l}\text { Content-dependent value. As the harder is the object, the longer } \\
\text { must be the } t \text { time }\end{array}$ \\
&
\end{tabular}




\subsection{Environment for Evaluation}

The work of Blom et al. (2013) proposes the next scenario for collaboration among students: "Imagine a lecture theatre. A student stands up and interrupts the teacher: "Excuse me sir, could you pause for three minutes, while I discuss with my neighbor what you just said?" What can hardly occur in normal lectures, takes place spontaneously, when watching video recordings of these lectures.". This scenario is not common in traditional classes, but it can easily occur when video lessons are used. Based on this idea, the schema of a VLE (Fig. 4) for small groups - CollabEduc - was specified and used to simulate our experiments.

This tool is composed of three parts:

- The video player frame (Fig. 4, top-left) enables access to learning objects in the form of video-classes, which has the content used as the basis for interactions.

- The whiteboard frame (Fig. 4, top-right) provides a resource to support the interactions. Mellingsæter (2015) stresses the use of virtual whiteboards as an important resource to improve the level of collaboration, since it enables the real-time visualization of ongoing solutions.

- The Chat frame (Fig. 4, bottom) supports the discussion of students by means of text messages.

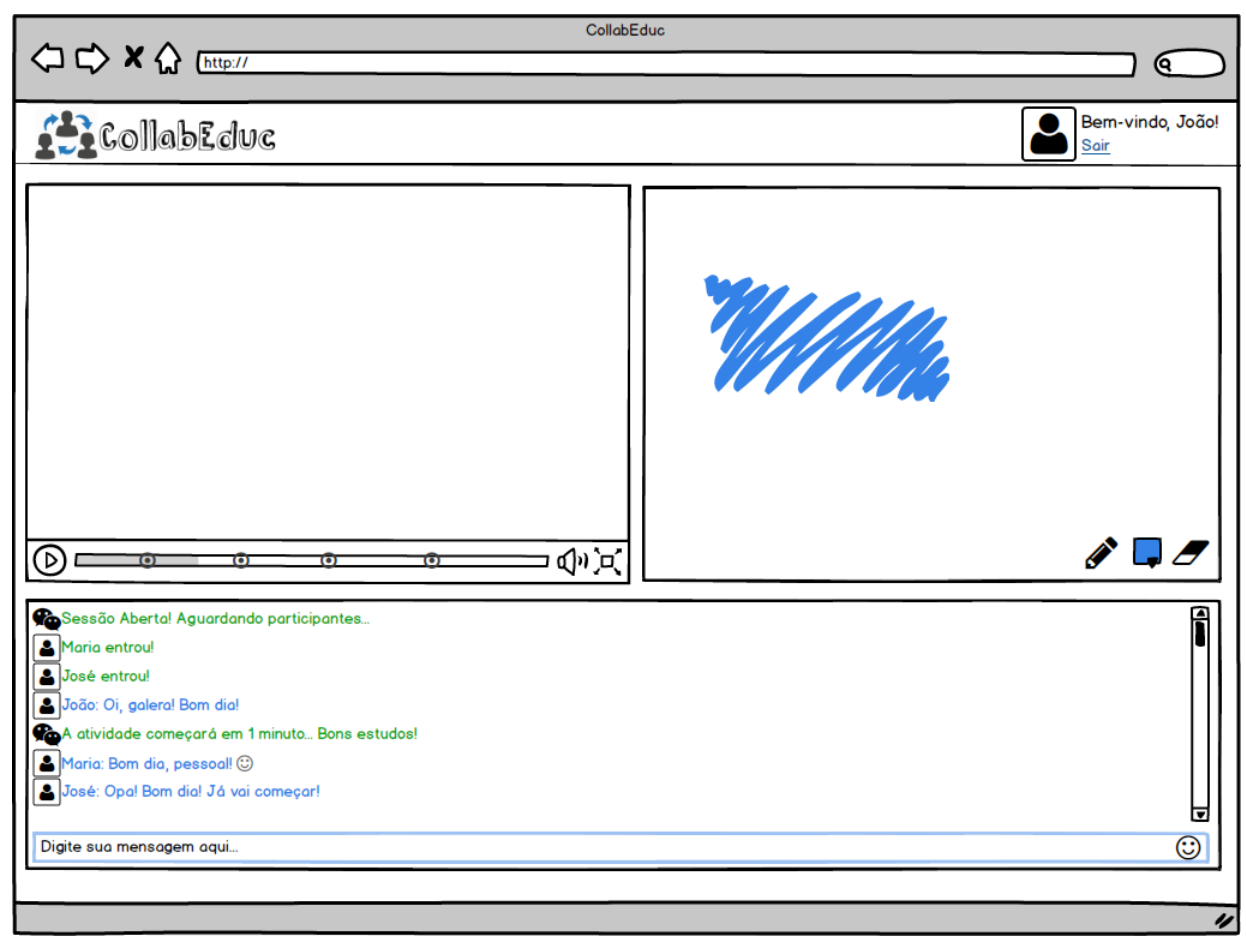

Fig. 4. CollabEduc - Virtual learning environment for collaboration in small groups. 


\section{Methodology}

\subsection{Purpose of the Study}

The hypothesis to be verified is: "The use of collaborative learning objects can induce collaborative behaviours in small groups of students and, thus, improve their learning process.". This hypothesis can be divided into two research questions: (1) Are collaborative learning objects able to induce collaborative behaviours among students? (2) Are collaborative learning objects able to improve the learning process?

\subsection{Participants}

The experimental study was conducted with 133 students from the first year of four TIC degrees (Computer Science, Electrical Engineering, Computational Mathematics, and Computer Engineering). The use of these different degrees was important to obtain higher diversity concerning the profile of students. Moreover, these 133 students represent about $22.8 \%$ of the students that attend, in each semester, the course of Introduction to Programming, whose content was used in the present experiments. The participation was restricted to students with none previous knowledge about programming and the experiments were conducted at the very beginning of the course to ensure the students have the same level of knowledge in this content.

\subsection{Research Design}

The experiments employed a quasi-experimental research design to address these research questions, similarly to Kurucay and Inan (2017). This type of design is generally used when the randomization of participants is not possible or not fine to compare students' performances in two different classrooms after an intervention (Bawden and Sonenstein, 1992). The 133 students were then assigned to the treatment (76 students) and control (57 students) groups. In order to control the confounding variables, a pre-survey measuring the students' perceptions of collaboration (interest, experience, and capability) was administered at the beginning of the study. This pre-survey was important because quasi-experimental research lacks the element of random assignment to treatment or control, so its design typically allows the researcher to control the assignment to the treatment condition but using some criterion other than random assignment (DiNardo, 2016). The present study used as criterion the balance of confounding variables listed above to divide the students into the two groups.

Students in the treatment group were clustered in 16 small groups with 4 or 5 members each. After that, students of the control group used the videos (without the collaboration strategies) to study the content and answer the revision activities. They could conduct this stage in their usual manner. Meanwhile, the treatment group used the CollabEduc-based resource. This means, they conducted the activities in small groups and supported by the learning objects that induced collaboration among them. 


\subsection{Data Source and Instrumentation}

Apart from the pre-survey, three other instruments were used to collect data from the experiments. The first instrument was a traditional exam regarding the content (programming introduction) presented to all students. This exam was conducted after the classes using the video lessons. This instrument generated quantitative data, which was analysed to support the conclusions about the impact of the approach on the learning process of students. The second instrument was a post-survey (see Table 5), which was applied to students of the treatment group to obtain their level of acceptability concerning the intervention. This survey was extended from the instrument of Hiltz (1988) and it has 13 items, some of them reverse scored, with a 5-Likert scale (SD - strongly disagree, D - disagree, $\mathrm{N}$ - neutral, A - agree, SA - strongly agree). The original instrument's internal reliability coefficient is 0.90 (high). Finally, the third instrument was a questionnaire-guideline for conducting observations. This instrument was used by tutors who assisted the execution of the experiments, while observed the behaviour of the students. Apart from direct observation, we also included artefact analysis such as the logs of devices that students used throughout the day. In fact, these logs (e.g. messages exchanged) were important as evidence about the collaborative behaviour of students.

\section{Results}

\subsection{Pre-survey}

The next graphs (Fig. 5) present the vision of the students concerning study groups (presurvey). The answers are related to the following questions:

(1) Have you already participated in any study group?

(2) Do you think participation in study groups could improve your grades?

(3) Are you motivated to join study groups?

(4) Do you think you could spontaneously use a tool to support online study groups?

The answers show the majority of the students have already participated in study groups and a high percentage of students $(97.1 \%)$ believe this form of study can im-
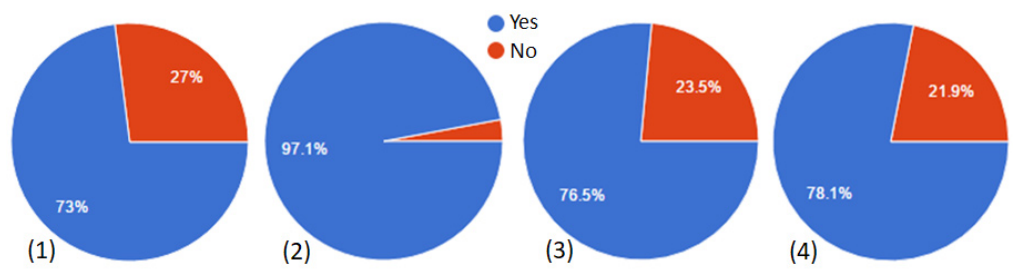

Fig. 5. Summary of some question of the pre-survey. 
prove their performance. However, this percentage decreases to $76.5 \%$ and $78.1 \%$ when the questions are respectively related to the motivation to join study groups and use of tools to support such groups. This seems a contradiction because if someone believes in a strategy they should be motivated to use this strategy. However, further discussions showed that problems to define a proper timeline that attends all participants tend to create barriers to this approach. An additional question in this stage was: "In your opinion, which is the ideal number of participants in a study group?". The main answers were $4(45.9 \%), 3(24.4 \%)$ and $5(22.2 \%)$. Thus, the students agree the strategy of small groups (between 3 and 5 students) is the best option.

\subsection{Student Performance}

The next results are related to the performance of the students. The average grade of the 57 students in the control group was 7.16, while Table 4 shows the average grade of the 16 small groups $\left(\mathrm{SM}_{\mathrm{i}}\right)$. According to this table, only four (SM03, SM09, SM11, SM12) from sixteen small groups had grades lower than the average of the control group. Thus, this result suggests that the strategies for collaboration may have some positive influence on the grades of the students. However, more experiments should be conducted to better support this affirmation. Table 4 also shows the small groups present a low standard deviation, apart from $\mathrm{SM}_{11}$. This indicates that the students obtained a more homogeneous level of knowledge about the content, which suggests that they shared their knowledge through the interactions. The standard deviation of the control group, for example, was 1.383179061 . This value is higher than the highest value of the small groups $\left(\mathrm{SM}_{11}=1,274754878\right)$.

Then, considering the previous question "Are the collaborative learning objects able to improve the learning process?", the data (grades) only suggests that the collaborative learning process may improve the knowledge acquisition of students. However, the learning process is improved in the sense that students have more opportunities to share their knowledge with peers so the group presents a level of knowledge more homogenous.

Table 4

Average grades and standard deviations of the 16 small groups

\begin{tabular}{lll}
\hline $\mathrm{SM}$ & Grade average & Standard Deviation \\
\hline $\mathrm{SM}_{01}$ & 7.68 & 0.294957624 \\
$\mathrm{SM}_{02}$ & 7.62 & 0.414728827 \\
$\mathrm{SM}_{03}$ & 6.30 & 0.570087713 \\
$\mathrm{SM}_{04}$ & 8.00 & 0.500000000 \\
$\mathrm{SM}_{05}$ & 8.32 & 0.540370243 \\
$\mathrm{SM}_{06}$ & 7.50 & 0.707106781 \\
$\mathrm{SM}_{07}$ & 8.32 & 0.460434577 \\
$\mathrm{SM}_{08}$ & 7.54 & 0.456070170 \\
\hline
\end{tabular}

\begin{tabular}{lll}
\hline $\mathrm{SM}$ & Grade average & Standard Deviation \\
\hline $\mathrm{SM}_{09}$ & 7.00 & 0.612372436 \\
$\mathrm{SM}_{10}$ & 7.50 & 0.500000000 \\
$\mathrm{SM}_{11}$ & 7.00 & 1.274754878 \\
$\mathrm{SM}_{12}$ & 6.88 & 0.630079360 \\
$\mathrm{SM}_{13}$ & 8.32 & 0.641872261 \\
$\mathrm{SM}_{14}$ & 8.32 & 0.766159252 \\
$\mathrm{SM}_{15}$ & 7.76 & 0.512835256 \\
$\mathrm{SM}_{16}$ & 8.32 & 0.732802838 \\
\hline
\end{tabular}




\subsection{Students Acceptance}

The next results (Table 5) show the students' answers to the post-survey. The results show the strategies had good acceptability and they were easy to use (Questions 01, 02, 03, 06, 07 and 08). However, a few students indicated that the presence of technical personal is important during the initial use of the tool (Question 04). A few students also indicated that the strategies are inconsistent because they are not always able to induce collaboration (Question 05). For example, the mutual regulation allows that each student creates part of the solution. However, if a student is not engaged in the process, then she/he simply can wait for the time conclusion of her/his turn rather than evolving the solution. In order, if a student does not feel comfortable to study in a group, none strategy for collaboration support will work well.

Students that negatively answered Questions 10,11, 12 and 13 indicated as the main reasons for their answers were socialization issues and preference for individual study (easy to concentrate). However, these answers were minority when compared with the positive (agree and strongly agree) options. Finally, 27.7\% of students agree that they need to learn other concepts to use this resource (Question 09). This percentage was considered high and the main reasons were the difficulty to understand the idea behind mutual regulation and the difference between argumentation and explanation.

Table 5

Percentage of answer to the post-survey according to the Likert scale (SD - strongly disagree, $\mathrm{D}$ - disagree, $\mathrm{N}$ - neutral, A - agree, SA - strongly agree)

\begin{tabular}{|c|c|c|c|c|c|c|}
\hline \# & Question & SD & $\mathrm{D}$ & $\mathrm{N}$ & A & SA \\
\hline 01 & I would like to use a resource with such strategies & $1.3 \%$ & $2.6 \%$ & $18.4 \%$ & $38.2 \%$ & $39.5 \%$ \\
\hline 02 & I think a resource with these strategies could be complex & $25 \%$ & $26.3 \%$ & $25 \%$ & $13.2 \%$ & $10.5 \%$ \\
\hline 03 & I think the strategies are easy to understand & $2.6 \%$ & $5.3 \%$ & $19.7 \%$ & $36.8 \%$ & $35.5 \%$ \\
\hline 04 & $\begin{array}{l}\text { I would need support from a technical person to be able to } \\
\text { use a resource with these strategies }\end{array}$ & $32,9 \%$ & $23,7 \%$ & $26,3 \%$ & $10,5 \%$ & $6,6 \%$ \\
\hline 05 & I think there are several inconsistences in the strategies & $38,2 \%$ & $15,8 \%$ & $38,2 \%$ & $6,6 \%$ & $1,3 \%$ \\
\hline 06 & $\begin{array}{l}\text { I think the majority of persons could quickly learn to use } \\
\text { this resource }\end{array}$ & $0,0 \%$ & $13,2 \%$ & $19,7 \%$ & $48,7 \%$ & $18,4 \%$ \\
\hline 07 & $\begin{array}{l}\text { I think a resource with these strategies could be very } \\
\text { complicated to use }\end{array}$ & $50,0 \%$ & $32,9 \%$ & $11,8 \%$ & $3,9 \%$ & $1,3 \%$ \\
\hline 08 & I felt myself very confident during the use of this resource & $6,6 \%$ & $2,6 \%$ & $44,7 \%$ & $30,3 \%$ & $15,8 \%$ \\
\hline 09 & $\begin{array}{l}\text { I need to learn several other concepts to use this resource } \\
\text { and strategies }\end{array}$ & $44,7 \%$ & $17,1 \%$ & $10,5 \%$ & $21,1 \%$ & $6,6 \%$ \\
\hline 10 & $\begin{array}{l}\text { I felt motivated to interact with my colleagues using these } \\
\text { strategies }\end{array}$ & $5,3 \%$ & $2,6 \%$ & $17,1 \%$ & $21,1 \%$ & $53,9 \%$ \\
\hline 11 & I did not enjoy the interactions using the strategies & $55,3 \%$ & $27,6 \%$ & $9,2 \%$ & $3,9 \%$ & $3,9 \%$ \\
\hline 12 & $\begin{array}{l}\text { I think my learning process was more effective using the } \\
\text { strategies }\end{array}$ & $1,3 \%$ & $5,3 \%$ & $22,4 \%$ & $34,2 \%$ & $36,8 \%$ \\
\hline 13 & $\begin{array}{l}\text { I could not see evolutions in my learning when I used these } \\
\text { strategies }\end{array}$ & $52,6 \%$ & $19,7 \%$ & $18,4 \%$ & $7,9 \%$ & $1,3 \%$ \\
\hline
\end{tabular}




\subsection{Analysis of the Tutors' Observations}

The final analysis was based on the logs and annotations of tutors who observed the behaviour of some participants. The main findings were:

- Argumentation experiment: $53.32 \%$ of the students did not agree with the first answer given to the problems. Thus, in about half of the cases, the students needed to interact to converge in their answers. In such cases, the majority of the students $(89.6 \%)$ collaborated to reach a consensus. This means they sent some type of message that could assist the process of convergence to a unique answer.

- Explanation experiment: $98.3 \%$ of the students provided some type of explanation, trying to contribute to the definition of solutions.

- Mutual regulation experiment: $75.43 \%$ of the students maintained their attention on the resolution of the questions since they were able to continue such a resolution in their turn. This experiment also presented some problems because $68.18 \%$ of the students did not follow the protocol and tried to interrupt the contribution of other participants, trying to assist them. Moreover, participants in their turn also tried to interact with their partners to better understand, for example, the current stage of the solution. In the end, only 3 participants were not able to give any contribution.

According to the annotations of the tutors, the students indicated the argumentation strategy as the most interesting and efficient, since they first try to individually answer a question and, after that, confront the results. Thus, they already have a detailed idea about the whole question and this fact facilitates the reasoning process concerning to accept or reject other arguments. Considering the previous question "Are the collaborative learning objects able to induce collaborative behaviours among students?", the data shows the students obtained a level of collaboration hard to normally be reached in VLEs that only present traditional resources for collaboration, mainly when we consider that such students are starting their degrees and did not have time to develop close friendships. This idea could be confirmed by the behaviour of the control group where students did not start any spontaneous interaction with their peers. In fact, the exchange of messages in this group was only observed between students and their tutors.

\section{Discussion}

Distance education brings several barriers to the development of collaborative behaviour. Apart from the problem of organizing individual timelines, students also reported that they usually do not maintain strong relationships with each other. Most of them never saw their colleagues "face-to-face". Moreover, several cases of frustrations concerning previous experiences in study groups were also reported and they demotivated this approach. The study of Noguera et al. (2018) corroborates this affirmation. According to the authors, "Unsatisfactory prior experiences in collaborative learning influence students' predisposition towards team-based learning activities. Incorporating 
strategies for helping teams to effectively regulate group work and enhance planning processes may result in an increase in students' engagement with learning activities and collaborative processes.". Vogel et al. (2018) also stresses the importance of using online environments with strategies that assist learners in collaborative development and application of knowledge.

The strategies discussed in the present study follow these ideas and they are alternatives to induce collaboration in VLEs. Their implementation as learning objects, which employ videos as the main educational resource, is very natural since such a type of object is massively used in VLEs and already usual for students. The results from post-survey (Table 5) show the good acceptance of the strategies by the students and the logs/annotations confirmed this aspect. This means the strategies can induce collaboration and students maintain their engagement during the process. This is also confirmed by the data collected from the observations of tutors. However, part of the students still prefers to study alone. Several reasons were discussed, such as fewer distractions, control over the study environment, and control over the study schedule. Moreover, the literature (Cassidy, 2004) shows that students' achievement increases when teaching methods match their learning styles (biological and developmental characteristics that affect how they learn). Thus, the use of collaborative learning objects can induce collaborative behaviours in small groups of students, but their learning process may be only improved if they have learning styles that are compatible with this type of collaborative approach. Oflaz and Turunc (2012) conducted an experimental study that illustrates this effect of learning styles on collaborative activities. Further aspects also demotivate the group study. For example, when the group is getting too talkative, its meetings keep getting rescheduled, and the student has a very different level of understanding than the group. This latter topic (group formation) is very important and the literature brings some studies that show how study groups should be composed (Chen and Kuo, 2019).

From the perspective of the lecturer, these strategies bring additional issues concerning the creation of learning objects. Argumentation learning objects are traditional Interactive-video quizzes. The manager system accounts for identifying different answers among students and starting the process of argumentation. Similarly, mutual regulation learning objects are also traditional videos followed by a final activity. The unique issue is to properly set the turn time $(t t)$. Differently, the explanation learning object is more challenging because the lecturer must choose a topic and create videos about complementary parts of this topic so each part becomes essential to the resolution of the final activity. Consider, for example, one of the activities used in our experiments:

The content related to this question was divided into 5 parts: (1) the programming environment, (2) input/output commands and their optional forms, (3) loop commands, (4) conditional commands, and (5) notations for variable declaration and primitive operations. Then, each of these parts was sent to a student, who should share his/her knowledge with their peers to conclude the activity.

An important feature of this approach is its generality concerning how to deliver knowledge. For example, the experiments of this paper were based on the content of a language programming course. However, the same structures (Figures 1, 2 and 3) could 
be used for courses of Social, Health or any other knowledge area since the approach can be seen as general patterns to arrange the delivery of educational contents. However, we are aware that the creation of collaborative learning objects may be easier or more complicated according to the particularities of each discipline. For example, while the idea of mutual regulation is natural when a solution is being prepared to a question about a historical fact (e.g. Fall of the Roman Empire); the creation of mutual regulation learning objects may require more creativity when it is related to the content of Anatomy. This relation between the particularities of the knowledge areas (e.g. factual, conceptual, procedural, or metacognitive) and their adequacy to the individual or collaborative learning is a research direction that could be derivate from this study.

This present study also presents two main limitations. First, the assessment of the level of collaboration is manual and subjective. When this process is carried out in a VLE, the logs are the main source of information, but only the number of exchanged messages is not an indicator of collaboration. A session can present a high number of messages but such messages may not aggregate to the collaborative behaviour. Thus, a qualitative analysis of the messages is required to decide which messages have some type of contribution to the group. Second, the annotations of the tutors are related to a small number of students ( 28 from 76 ) because the tutors should be together with the students to observe their behaviour and this was not possible during the whole experiments. The use of cameras is a possible solution to this problem because the same group of researchers could simultaneously observe the behaviour and motivation of different students that are geographically dispersed.

\section{Conclusion}

Based on the previous discussions, the initial questions can be answered as follows.

Q1 - Which concepts could be used to induce collaboration in educational settings? This study presented three concepts, or forms of interaction, that can be used to induce collaboration in small groups: argumentation, explanation, and mutual regulation. These concepts have a proper theoretical basis from the Social and Educational Psychology areas, but their practical use was not evaluated in learning environments.

Q2 - Which educational theories support these concepts? These concepts (argumentation, explanation, and mutual regulation) were extracted from educational theories and, consequently, they have a theoretical basis that is focused on supporting and motivating the collaborative behaviour inside the educational context. Thus, our study is similar to other investigations that use formal theories as the basis to create practical resources that could be deployed in VLEs. Differently, however, we analysed theories that were never used or evaluated in VLEs.

Q3 - How should be the specification of learning objects based on these concepts? Learning objects are the basic building blocks of modern e-learning systems that intend to disseminate and reuse knowledge. Moreover, they represent a conceptualization that is already established over the e-learning community. Thus, the present study proposed 
the implementation of collaboration concepts (argumentation, explanation and mutual regulation) in the form of learning objects, particularly based on interactive-videos. The structure of these videos is defined according to the collaboration concepts and such a structure can be used to represent pierces of knowledge of any domain. Section 4.3 showed that students had a very good acceptance of this proposal, while Section 4.4 showed that such objects can in fact promote collaboration among students. Thus, the results demonstrate that this proposed specification attends its initial objectives. As videos, other popular resources of VLEs were already used to support collaboration, such as assessments. However, studies showed that assessments, for example, did not generate a significant difference in learners' participation since they were not considered as a natural resource to promote collaboration.

Q4 - How could these objects be used in a Virtual Learning Environment? Section 2.5 showed a prototype that could be used as a learning resource and be included in VLEs as plugins. Its main function was to control the flow of interactions (e.g. time of contributions - turn time - during the execution of mutual regulation learning objects) and provide a virtual space for joint discussions. A particular contribution in this virtual space is the use of virtual whiteboards. While they were used as a final tool for collaboration support; we extended this concept by using whiteboards as part of a more general collaborative framework, where whiteboards are not the principal player but just a further resource to augment the possibilities for collaboration. The results of Sections 4.3 and 4.4 demonstrate the positive results of this strategy.

The results of the experiments showed that the learning objects can induce collaborative behaviours among students and suggest that such collaboration may improve the level of students' learning. However, further experiments must be conducted to collect more evidences that support this latter affirmation. Research directions intend to create tools that facilitate the creation of collaborative learning objects and conduct longitudinal studies that show the impact of these strategies in the grades of students.

\section{Acknowledgement}

This study was financed in part by the Coordenação de Aperfeiçoamento de Pessoal de Nível Superior - Brasil (CAPES) - Finance Code 001

\section{References}

Amory, A. (2013). The Collaboration-Authentic Learning-Tool Mediation (CAT) Framework: The Design, Use and Evaluation of an Academic Professional Development Workshop. In: Proceedings of EdMedia 2013World Conference on Educational Media and Technology, 449-457.

Aronson, E. et al. (1978). The Jigsaw Classroom. Beverly Hills, CA: Sage Publications.

Ayala, G., Castillo, S. (2008). Towards computational models for mobile learning objects. In: Fifth IEEE International Conference on Wireless, Mobile, and Ubiquitous Technology in Education (pp. 153-157).

Bawden, D.L., Sonenstein, F.L. (1992). Quasi-experimental designs. Children and Youth Services Review, 14(1), 137-144.

Benitti, F.B.V. (2018). A methodology to define learning objects granularity: a case study in software testing. In- 
formatics in Education, 17(1), 1-20.

Brindley, J., Walti, C., Blaschke, L. (2009). Creating effective collaborative learning groups in an online environment. The International Review of Research in Open and Distance Learning, 10(3), 1-18.

Blom, J., Verma, H., Li, N., Skevi, A., Dillenbourg, P. (2013). MOOCs are more social than you believe. eLearning Papers, 33.

Burbaite, R., Stuikys, V., Damasevicius, R. (2013, July). Educational robots as collaborative learning objects for teaching computer science. In: 2013 International Conference on System Science and Engineering (pp. 211-216).

Caballé, S., Gañán, D., Dunwell, I., Pierri, A., Daradoumis, T. (2012). CC-LO: Embedding interactivity, challenge and empowerment into collaborative learning sessions. J. UCS, 18(1), 25-43.

Cassidy, S. (2004). Learning styles: An overview of theories, models, and measures. Educational Psychology, 24(4), 419-444.

Chen, P., Gonyea, R., Kuh, G. (2008). Learning at a distance: Engaged or not? Innovate, 4(3).

Chen, C., Kuo, C. (2019). An optimized group formation scheme to promote collaborative problem-based learning. Computers \& Education, 133, 94-115.

Choi, H.J., Park, J. (2018). Testing a path-analytic model of adult dropout in online degree programs. Computers \& Education, 116, 130-138.

Cruz-Flores, R., López-Morteo, G. (2008). A model for collaborative learning objects based on mobile devices. In: 2008 Mexican International Conference on Computer Science (pp. 89-95).

Dillenbourg, P., Baker, M., Blaye, A., O'Malley, C. (1996). The evolution of research on collaborative learning. In: E. Spada, P. Reiman (Eds.), Learning in Humans and Machine: Towards an Interdisciplinary Learning Science. Elsevier, pp. 189-211.

DiNardo, J. (2016). Natural experiments and quasi-natural experiments. The New Palgrave Dictionary of Economics, $1-12$.

Finegold, A., Cooke, L. (2006). Exploring the attitudes, experiences and dynamics of interaction in online groups. The Internet and Higher Education, 9(3), 201-215.

Fuentes, L.M., Arteaga, J.M., Rodriguez, F.Á. (2008). A methodology for design collaborative learning objects. In: 2008 Eighth IEEE International Conference on Advanced Learning Technologies (pp. 87-91).

Gayatan, J., McEwen, B. (2007). Effective online instructional and assessment strategies, American Journal of Distance Education, 21(3), 117-132.

Hernandez, N., Mothe, J., Ralalason, B., Ramamonjisoa, B., Stolf, P. (2008). A model to represent the facets of learning object. Interdisciplinary Journal of E-Learning and Learning Objects, 4(1), 65-82.

Hiltz, S.R. (1988). Teaching in a virtual classroom. A Virtual Classroom on EIES: Final Evaluation Report (Vol. 2). Newark, NJ: New Jersey Institute of Technology.

IEEE (2002). Draft Standard for Learning Object Metadata. Learning Technology Standards Committee of the IEEE. [S.1.] (IEEE 1484.12.1-2002).

Juwah, C. (2006). Interactions in online peer learning. In: R.C. Sharma, C. Juwah (Eds.) Interactions in Online Education. Implications for Theory and Practice (pp. 171-190). New York: Lawrence Erlbaum.

Kearsley, G. (2000). Online Education: Learning and Teaching in Cyberspace. Belmont, CA: Wadsworth.

Koohang, A. (2004). Creating learning objects in collaborative e-learning settings. Issues in Information Systems, 4(2), 584-590.

Kumar, M., Singh, A., Handa, D. (2017). Literature survey on educational dropout prediction. International Journal of Education \& Management Engineering, 2, 8-19.

Kurucay, M., Inan, F.A. (2017). Examining the effects of learner-learner interactions on satisfaction and learning in an online undergraduate course. Computers \& Education, 115, $20-37$.

Lin, Y., Wu, C., Chiu, C. (2018). The use of Wiki in teaching programming: Effects upon achievement, attitudes, and collaborative programming behaviors. International Journal of Distance Education Technologies (IJDET), 16(3), 18-45.

Mellingsæter, M. (2015). Meaning making through use of interactive whiteboards during physics group work. A case study from engineering education. Nordic Studies in Science Education. 11. 135. 10.5617/nordina.973.

Mirza, N.M., Perret-Clermont, A. (2009). Argumentation and Education: Theoretical Foundations and Practices. Dordrecht, Heidelberg, London, New York: Springer.

Money, W.H., Dean, B.P. (2019). Incorporating student population differences for effective online education: A content-based review and integrative model. Computers \& Education, 138, 57-82.

Noguera, I., Guerrero-Roldán, A.E., Masó, R. (2018). Collaborative agile learning in online environments: Strategies for improving team regulation and project management. Computers \& Education, 116, 110-129.

Oflaz, M., Turunc, T. (2012). The effect of learning styles on group work activities. Procedia-Social and Behavioral Sciences, 46, 1333-1338. 
Palloff, R., Pratt, K. (2005). Collaborating online: Learning together in community. San Francisco, CA: JosseyBass.

Piaget, J. (1985). The Equilibration of Cognitive Structures: The Central Problem of Intellectual Development. University of Chicago Press.

Randolph, J.J. (2007). What's the difference, still? a follow up methodological review of the distance education research. Informatics in Education, 6(1), 179.

Siemens, G. (2004). Connectivism: A Learning Theory for the Digital Age. Retrieved from http://www .itdl .org/journal/jan_05/article01.htm

Springer, L., Stanne, M., Donovan, S. (1999). Effects of small-group learning on undergraduates in science, mathematics, enginnering, and technology: A meta-analysis. Review of Educational Research, 69(1), 2151.

Stürmer, S., Ihme, T.A., Fisseler, B., Sonnenberg, K., Barbarino, M.L. (2018). Promises of structured relationship building for higher distance education: Evaluating the effects of a virtual fast-friendship procedure. Computers \& Education, 124, 51-61.

Tseng, H., Yeh, H.T., Tang, Y. (2019). A close look at trust among team members in online learning communities. International Journal of Distance Education Technologies (IJDET), 17(1), 52-65.

Vogel, C., Hochberg, J., Hackstein, S., Bockshecker, A., Bastiaens, T.J., Baumöl, U. (2018). Dropout in distance education and how to prevent it. EdMedia + Innovate Learning (pp. 1788-1799).

Vygotskiĭ, L.S., In Hanfmann, E., In Vakar, G. (1962). Thought and Language. The MIT press.

Wilson, T.P. (1970). Conceptions of interaction and forms of sociological explanation. American Sociological Review, 35(4), 697-710.

Weidlich, J., Bastiaens, T.J. (2019). Designing sociable online learning environments and enhancing social presence: An affordance enrichment approach. Computers \& Education, 142, 103622.

Wengrowicz, N., Swart, W., Paul, R., Macleod, K., Dori, D., Dori, Y.J. (2018). Students' Collaborative Learning Attitudes and Their Satisfaction with Online Collaborative Case-Based Courses. American Journal of Distance Education, 32(4), 283-300.

E.F.C. Lima is part of the distance learning development team of the Mauricio de Nassau Faculty in Brazil. She received a MSc in Computer Science at the Federal University of Paraiba, with studies involving collaborative learning strategies for virtual environments. His current research interests focus on extensions for the Moodle platform and longitudinal experiments.

C.A. Siebra is an associate professor at the Federal University of Paraiba and a research collaborator at the CIn/Samsung Research and Development Lab in Brazil. He received a Ph.D. in artificial intelligence from the University of Edinburgh - UK, with studies involving multiagent intelligent planning. His current research interests focus on the use of knowledge-based techniques in the educational domain. 